\title{
Publishing SNP Genotypes of Human Embryonic Stem Cell Lines: Policy Statement of the International Stem Cell Forum Ethics Working Party
}

\author{
Bartha M. Knoppers • Rosario Isasi • Nissim Benvenisty • Ock-Joo Kim • \\ Geoffrey Lomax • Clive Morris • Thomas H. Murray • Eng Hin Lee • Margery Perry • \\ Genevra Richardson • Douglas Sipp • Klaus Tanner • Jan Wahlström • \\ Guido de Wert • Fanyi Zeng
}

Published online: 29 January 2011

(C) The Author(s) 2011. This article is published with open access at Springerlink.com

\begin{abstract}
Novel methods and associated tools permitting individual identification in publicly accessible SNP databases have become a debatable issue. There is growing concern that current technical and ethical safeguards to protect the identities of donors could be insufficient. In the context of human embryonic stem cell research, there are no studies focusing on the probability that an hESC line donor could be identified by analyzing published SNP profiles and associated genotypic and phenotypic information. We present the International Stem Cell Forum (ISCF) Ethics Working Party's Policy Statement on "Publishing SNP Genotypes of Human Embryonic Stem Cell Lines (hESC)". The Statement prospectively addresses issues surrounding the publication of genotypic data and associated annotations of hESC lines in open access databases. It proposes a balanced approach between the goals of open
\end{abstract}

B. M. Knoppers

International Stem Cell Forum Ethics Working Party. Centre of

Genomics and Policy, Faculty of Medicine, Department of Human

Genetics McGill University,

740 Dr. Penfield Avenue, Rm 5214,

Montreal, QC H3A 1A4, Canada

R. Isasi $(\square)$

International Stem Cell Forum Ethics Working Party. Centre of

Genomics and Policy, Faculty of Medicine, Department of Human

Genetics McGill University,

740 Dr. Penfield Avenue, Rm 5206,

Montreal, QC H3A 1A4, Canada

e-mail: Rosario.isasi@mcgill.ca

N. Benvenisty

The Herbert Cohn Chair in Cancer Research, Stem Cell Unit, Institute of Life Sciences, The Hebrew University of Jerusalem, Givat-Ram,

Jerusalem 91904, Israel science and data sharing with the respect for fundamental bioethical principles (autonomy, privacy, beneficence, justice and research merit and integrity).

Keywords Embryonic stem cells · Data sharing · Ethics . Policy · Databases $\cdot$ SNPs $\cdot$ Genotypic data

The International Stem Cell Initiative (ISCI) [1]—-launched under the auspices of the International Stem Cell Forum (ISCF) [2] - is a worldwide collaborative effort to establish basic criteria and techniques to underpin the development of applications for hESC in human medicine. The Initiative has collected comprehensive background information on individual cell lines (e. g. derivation and maintenance conditions) in order to systematically study hESC in an effort to establish international standards for characterization.

\section{O.-J. Kim}

Department of Medical History and Medical Humanities, College of Medicine Seoul National University,

Jongno-gu Yongun-dong 28,

Seoul 110-799, Korea

G. Lomax

California Institute for Regenerative Medicine,

210 King Street,

San Francisco, CA 94107, USA

C. Morris

National Health \& Medical Research Council,

GPO Box 1421, Canberra ACT 2601, Australia

T. H. Murray

The Hastings Center,

21 Malcolm Gordon Road,

Garrison, NY 10524, USA 
The data from ISCI form the basis for the ISCI Human ES Cell Registry [3]. It is used as a reference in other stem cell registries such as the European hESCreg.

The ISCI is characterizing genotypically different hESC lines isolates using high density Illumina BeadArrays to interrogate the samples for a range of genomic features. The particular BeadArray chosen is the HUMAN 1M-DUO v3. The 1M-DUO array provides a very high coverage of genome markers in general and in particular single nucleotide polymophisms (SNP's). This high density coverage means that very detailed information about a cell line's genotype will be gathered, and by implication also about the donors of the gametes or of other cells that gave rise to the cell lines.

In contrast to the genotype of cell lines derived from a single donor, the genotype of a hES cell does not correspond directly to the genotype of the individuals who donated the embryo from which the hES cell line was derived. There is effectively no possibility of donor identification based solely upon the genotype of a hESC line, and hence, the genotype of the embryo from which it was derived. Nevertheless, it may still be possible to infer some genomic information about the gamete donors. Under remote circumstances and solely when additional information is available regarding the donation (e.g. date, place of embryo donation together with information about the genotype of the donor) might it be possible to identify a donor.

For the immediate purposes of the ISCI study, it is not necessary to identify the genotypes of individual cell lines, but rather to present conclusions derived from aggregating the individual data. However, upon completion of the project, the International Stem Cell Initiative (ISCI) will be in possession of scientifically useful information about the genotypes of the individual cell lines which could be

\footnotetext{
E. H. Lee

Division of Graduate Medical Studies, Faculty of Medicine, Yong Loo Lin School of Medicine, National University of Singapore, Block MD5, 12 Medical Drive,

Kent Ridge S(117598), Singapore

M. Perry

JDRF, Lay Review Committee,

P.O. Box 3382, Aspen, CO 81612, USA
}

G. Richardson

School of Law, King's College,

London Strand,

London WC2R 2LS, UK

D. Sipp

Riken Center for Developmental Biology,

Science Policy and Ethics Studies Unit,

2-2-3 Minatojima-minamimachi, Chuo-ku Kobe 650-0047, Japan published in the scientific literature and may be lodged in the ISCI Human ES Cell Registry.

Novel methods and associated tools — such as the ones described above -permitting individual identification in publicly accessible SNP databases have become a debatable issue $[4,5]$. There is concern that established safeguards to protect the identities of donors could be insufficient [6]. In the context of stem cell research, however, there are no studies focusing on the probability that similar methods and tools could be used to identify a hES cell line donor by analyzing published SNP profiles and associated phenotypic information.

It is the sense of the EWP that the likelihood of revealing donor identity is remote. While revealing donor identity is improbable, potential donors should be made aware that genotypic data may be in the public domain. However, in an area of research moving toward therapies and where donors of embryos provided hES cells under conditions of anonymity, a proportional approach to privacy requires examining the probability of identifiability as well as the balancing of risks and benefits. As stated by the Data Protection Working Party of the European Commission, Opinion 4/2007:

“... a mere hypothetical possibility to single out the individual is not enough to consider the person as "identifiable". If, taking into account "all the means likely reasonably to be used either by the controller or by any other person" that possibility does not exist or is negligible, the person should not be considered as "identifiable" and the information would not be considered as "personal data" [7].

Thus, it is the view of the EWP that already existing hESC lines should be placed in open access databases if in the opinion of their curator there is no reason to believe that

K. Tanner

Wissenschaftlich-Theologisches Seminar, Heidelberg University, Kisselgasse 1, 69117 Heidelberg, Germany

\section{J. Wahlström}

Department of Medical Genetics, University of Gothenburg, Klinisk genetic SU/Sahlgrenska, 41345 Göteborg, Sweden

\section{G. de Wert}

Department of Health, Ethics and Society, Faculty of Health, Medicine and Life Sciences, Maastricht University,

P.O. Box 616, 6200 MD Maastricht, The Netherlands

F. Zeng

Shanghai Institute of Medical Genetics, Shanghai Stem Cell Institute, Shanghai Jiao Tong University School of Medicine, 280 S. ChongQing Road. Bldg 5, Room 707,

Shanghai 200025, People's Republic of China 
such data should not be made public, and that their publication complies with both the donor's original informed consent and with national regulations.

The overall aim of the International Stem Cell Forum is to promote global good practices through collaboration in stem cell research. While recognizing ethical and legal constraints, the ISCF supports the sharing of data with the international community to accelerate progress in this vitally important area of biomedical science. The ISCF is respectful of the privacy of the individuals who contribute to the advancement of the field via the donation of their biological materials. To achieve these aims, while respecting fundamental bioethical principles such as beneficence, justice and research merit and integrity, the ISCF EWP recommends the following policy:

\section{ISCF Ethics Working Party Policy Statement}

The goal of open science and the principle of transparency argue in favour of maintaining open access databases, even when faced with scenarios of possible-yet extremely unlikely-identification of donors. In the future, all genotypic data and associated annotations arising from the International Stem Cell Initiative (ISCI) should be organized and placed in an Open Access Database. Thus, the ISCF EWP encourages the scientific community to prospectively adopt appropriate broad informed consent protocols to govern future stem cell research involving genotypic information. To that end, such consent should foresee genotypic data eventually being placed in open access databases. Where possible, it should prospectively seek explicit consent for donor SNP data to be published in open access databases on the internet. However for already existing lines, we also endorse open access databases where there is no reason to believe that such publication would contravene donor consent or applicable laws.

Acknowledgments The authors are especially grateful to Dr. Peter W. Andrews, Dr. Paul Gokhale, Dr. Alan Colman and Dr. Glyn Stacey for the valuable scientific advice they provided to the EWP during the drafting of this Policy Statement. However, the opinions expressed are those of the authors alone.

Conflict of Interest This project was supported, in part, by the International Stem Cell Forum. Our funding sources have played no role in the design, interpretation, and writing of the present study.

Open Access This article is distributed under the terms of the Creative Commons Attribution Noncommercial License which permits any noncommercial use, distribution, and reproduction in any medium, provided the original author(s) and source are credited.

\section{References}

1. http://www.stemcellforum.org/isci_project.cfm.

2. http://www.stemcellforum.org/.

3. http://www.stemcellforum.org/isci_project/the_registry.cfm.

4. Homer, N., Szelinger, S., Redman, M., et al. (2008). Resolving individuals contributing trace amounts of DNA to highlight complex mixtures using high-density SNP genotyping mycroarrays. PLoS Genetics, 4(8).

5. Lin, Z., Altman, R. B., \& Owen, A. B. (2004). Genomic research and human subject privacy. Science, 305, 183.

6. $\mathrm{P}^{3} \mathrm{G}$ Consortium, Church, G., Heeney, C., et al. (2009). Public access to genome-wide data: five views on balancing research with privacy protection. PLoS Genetics, 4(10).

7. The working party on the protection of individuals with regard to the processing of personal data to the European Commission. Opinion 4/2007 on the Concept of Personal Data, 01248/07/EN WP 136 (June 20th, 2007). 